\title{
TYPES OF CAGES FOUND USEFUL IN PARASITE WORK
}

\author{
By C. E. Hoon, Dallas, Texas
}

In the breeding work connected with the boll weevil investigations the inability to carry through a large percentage of the weevils and parasites showed very plainly the inefficiency of the various types of cages which were then in use. It was therefore necessary to construct several new cages furnishing more nearly the natural conditions under which the various weevils and parasites live. The object of this paper is to give a brief description of these cages, their advantages, and some of the results already obtained from their use.

Most of the breeding work at Dallas, Texas, has been carried on out of doors in a remodelled hibernation cage. This consists of a frame of two by fours, measuring ten feet on each side and seven feet in height, the top and sides of which are covered with 14-mesh wire screen. A roof was built over this and shelves arranged for cages on three sides. With such a cage it was possible to produce more natural conditions of temperature and humidity than were possible before in the breed. ing room of the laboratory.

\section{Indoor Breeding Cages}

Of the various cages used, our five-section cage is the largest. This measures four and a half feet in length, ten inches in width and twelve inches deep. The bottom and ends are of wood, the top and back of 50 mesh wire gauze and the front of glass. T'his cage is divided into five sections by wooden partitions, each section being entirely separated from the others. The panes of glass in the front ean be raised or lowered and serve as doors. Pieces of felt-edged weather stripping are used in the grooves in which the glass slides to insure tightness.

This has proven to be a very satisfactory breeding cage. One disadvantage, however, is that the insects attracted to the light collect on the glass and it is impossible to get them without disturbing or oftentimes crushing some of them. This difficulty has been overcome almost entirely by having the side opposite the glass made of wood instead of wire, with a small door in the center large enough to admit the hand. To secure isolation from ants and mites, nails are driven part way up into the bottom of the cage, one on each corner, and the heads are set in small cups of vaseline or axle grease.

For smaller lots of material the box cage has proven to be quite satisfactory. This is a wooden box of the style used by the California Board of Horticulture. It is ten inches long, six inches wide and six 
inches deep. This box is fitted with two covers, the inner one glass, the outer one wood. With such an arrangement it is possible to examine the material without allowing the insects to escape. Three holes are bored in the front of the cage, one inch in diameter, and in these are placed glass tubes about four inches in length. Insects attracted to the light come out into the tubes, where they can be easily collected. A layer of sand on the bottom of the box makes conditions favorable for larve that enter the ground for pupation.

If it is desired to watch the larve that enter the ground they are put into the double tube cage. This consists of one tube inside of another, the inner tube having no bottom. Dirt is placed between the tubes and the outer tube is encased in black paper. Water placed in the middle tube passes through the dirt by capillarity, keeping the ground in a moist condition. This inner tube because of the light forces the larva to the outside of the outer tube, where they can be readily seen by removing the black paper.

Smaller lots of breeding material are kept in tumblers in which has been placed a layer of moist sand. The tops of the tumblers are covered with cheese cloth held in place by elastic bands.

In our parasite breeding work it is desirable to obtain correot data on the length of development of the various stages. In order to do this each specimen is isolated and so labelled that the data on the individual specimen can be referred to at any time. These specimens are isolated generally as larvæ or pupæ in glass tubes with cotton stoppers or in gelatine capsules.

The Dipterous parasites are somewhat harder to carry through to maturity because of the lack of proper conditions of moisture. This has been supplied by a new type of cage. It consists of a tray filled with about an inch of sand. Glass tubes without bottoms are placed in the sand in an upright position. By means of two of these tubes, which are filled with water, the sand near the bottom of the troy is kept wet, while the sand on the top is kept moist from this by capillarity. A single Dipterous larva is placed in each of the remaining tubes, the tops of which are closed with cotton stoppers.

\section{Plant Cages}

Perhaps the most interesting type of cage in use at the laboratory is the mica plant cage. This consists of a mica tube eight inches long and two and a half inches in diameter, such as are used as chimneys for gas lights. One end is closed with cheese cloth and on the other end a cuff of the same material is fitted so that the tube can be placed over the top of the plant and the loose end of the cuff tied tightly 
around the stem of the plant. On'the sides of the tubes are three small metal rings. Pieces of strong string or twine fastened to some support above the cage pass down and are secured to these rings. They then are continued downward and after being pulled taut are tied to the stem of the plant below, where the cuff is attached. In this way the strain caused by the swaying and blowing of the plant is not brought to bear on the cage but on the stem below the cuff and on the support above. On the side of the cage a small opening is made for the admission of parasites. It is closed by a mica slide or a cotton stopper. About three inches above the tube a circular piece of cardboard about eight inches in diameter is placed. This is to protect the cage from rain and also from the direct rays of the sun.

In using this cage for our parasite work, weevil-infested squares freshly punctured are tied to the top of the plant. The mica tube is then slipped on over them and the cuff is tied to the stem below. The twine is fastened to the support above and to the stem below the cuff, and lastly the parasites are admitted through the opening in the side.

Up to this time great difficulty had been experienced in perfecting a plant cage which did not sweat. In the use of this cage this fall under the most favorable conditions for sweating very little moisture collected in the tube. What little there was was soon taken up by the cheese cloth. This type of cage furnishes plenty of light and air, the parasites are abundantly supplied with nectar from the floral and other nectaries of the cotton plant for food and in every way they seem to feel perfectly at home.

Very few observations on the oviposition of Hymenopterous parasites, especially the Chalcidids, have been placed on record, but notwithstanding the fact that these cages were not put into use until about October 1st, notes on the oviposition of two species of Chalcidids and two species of Braconids have been made.

Another plant cage for similar work but very much larger was tried for a short time and seems to work equally as well as the mica cage. This cage is about a foot square and fifteen inches in height. It consists of a wooden framework with fifty mesh wire gauze on one side and a sliding glass door on the opposite side. The other two sides, the top and bottom are covered with cheese cloth. A cross piece divides the bottom of the cage equally. One half of the bottom is immovable, while into the other half a door is fitted which opens downward. A small hole is bored in the center where the edge of the door and the crosspiece meet. Into this the stem of the plant fits. Another small hole is bored in any available space in the frame work to admit the 
parasites and is closed with a cork stopper. Guy strings may conveniently be attached to prevent movement by the wind.

With this cage a larger portion of the plant can be enclosed, more squares ean be supplied and more parasites placed under observation. The very size, however, prevents as close observations as are possible in the smaller cage. The oviposition of Sigalphus curculionis has already been observed in this cage.

\section{Field Cages}

To facilitate the increase of parasites in the cotton field, cages of fourteen mesh wire are used, in which are placed the hanging or fallen infested squares. Wire of this mesh enables all of the parasites to escape, but only a very small percentage of the weevils.

This cage is fifteen inches square and three feet high. It is covered on all sides, top and bottom with fourteen mesh wire. Five wire shelves are built in this cage, five inches apart, and on these are placed the infested forms. These wire shelves allow a better circulation of air, which keeps the material drier and also prevents heating and molding. One entire side forms the door, giving access to all of the shelves. When in the field this cage is kept free from infestation by ants or mites by placing the legs in a zinc tray containing two or three inches of water.

Other types of cages have been made but as yet their usefulness has not been.proven by actual test.

President Forbes: Any questions to ask or discussion of this paper?

A Member: Mr. President, we had an interesting experience in trying to get parasites into tubes while studying a certain moth. We put them in a box fitted with glass tubes and we secured neither moths nor parasites. They had formed the habit of breeding in the dark and they would not come out to the light.

PRESIDENT Forbes: If there are no further remarks the next paper will be raad by Mr. Parrott.

\section{TREE CRICKETS AND INJURY TO APPLE WOOD}

By P. J. Parrott, Geneva, N. Y.

During the past two years our attention has been directed to discolored areas on apple limbs, which have the appearance of being the early stages of a canker. These diseased spots have usually a dark 